Note: This is a pre-copy-editing, author-produced PDF of an article accepted for publication in Substance Use \& Misuse following peer review. The definitive publisher-authenticated version [McElrath $\mathrm{K}$ and McEvoy K (2001) Fact, fiction and function: mythmaking and the social construction of ecstasy use, Substance Use \& Misuse, 36(1\&2), 1-22] is available online at http://www.informaworld.com/smpp/content $\mathrm{db}=\mathrm{all} \sim$ content $=\mathrm{a} 713733455$

\title{
FACT, FICTION, AND FUNCTION: MYTHMAKING AND THE SOCIAL CONSTRUCTION OF ECSTASY USE
}

\section{Karen McEIrath ${ }^{1}$ and Kieran McEvoy ${ }^{2}$}

\author{
${ }^{1}$ School of Sociology and Social Policy, The Queen's University, Belfast BT7 1NN, Northern Ireland \\ ${ }^{2}$ Institute of Criminology and Criminal Justice, The Queen's University, Belfast BT7 1NN, Northern \\ Ireland
}

Published in Substance Use \& Misuse (2001), 36(1\&2), 1-22

\begin{abstract}
Myths and folklore about drugs represent important aspects of user subcultures. This paper explores Ecstasy users' perceptions about drug folklore as it relates to the social relationships of drug user lifestyles. The data for the study were collected through in-depth interviews with 50 current or former Ecstasy users in Northern Ireland. The findings indicate that although some Ecstasy users perceive the folklore to be an accurate reflection of reality others report that social relations among users change with continued usage, occur within selected venues, or are influenced by greater cultural relations that characterize mainstream society.
\end{abstract}

\section{INTRODUCTION}

One of the enduring realities of drug use in the latter part of the 20th century that undoubtedly will characterize much of the 21 st century as well is the almost continuous introduction of new drug formulations that became available to social drug users. The advent of each new drug predictably is accompanied by a variety of conflicting societal messages about the advantageous or the deleterious effects of that drug (see Table 1 for a brief account of the emergence of psychotropic drugs). The sources of those messages are legion and reflect contemporary educational, ideologic, journalistic, legal, medical, moral, political, and religious perspectives of the era. In the presence of these multiple and often competing viewpoints, it is not unusual for policymakers to ignore the perspectives of the users themselves or to relegate popularized versions of their views to the status of unreliable folklore or myth.

In the past such rejection of users' experiences has produced inaccurate negative statements about drugs by governmental and public health authorities that have caused users to dismiss other governmental reports that were accurate. At other times users themselves have accepted uncritically the positive, popular folklore of a drug that has not been grounded in thorough examination of the experiences of the users of that drug or in the medical facts concerning the effects of the drug. Both of these failures to examine the users' perspectives can lead to uninformed, sometimes risky drug use behavior and/or poorly thought-out drug legislation.

The goal of this paper is to demonstrate how popular myths surrounding such drugs can be evaluated by a careful analysis of the self-reports of the experiences of a variety of users of those drugs. As we reach the end of this century, one of the most prominent drugs currently popular in several areas of the world is MDMA, which is known by the street name, Ecstasy (E). Although a patent for MDMA (3,4-methylenedioxymethamphetamine) was first issued in 1914 (4), the availability of $E$ as a street drug is quite recent, having gained in popularity in the 1980 s and 1990 s in England (6), Scotland (7), the United States (8), Australia (9), and in various European countries (10) [see (11) for a review of E use in several European countries]. 
MDMA is related structurally to amphetamine and may produce mild hallucinogenic effects that generally are not characterized by disorientation or major visual or audio distortions typically associated with other hallucinogens (12). Contemporary folklore suggests that $E$ use enhances empathy and generally improves social interactions among users, while the medical literature is heavy with case reports of negative psychiatric and physiologic effects. The purpose of this paper is to explore this contemporary myth by investigating ways in which $E$ users, who reside in a region of the world characterized by socially estranged communities, believe the use of $E$ does/does not impact their social relationships in that society. More specifically we focus on users' perceptions about the relationship between $E$ and social relationships, including:

- The existence of "loved up" feelings generally associated with E use;

- The presence/absence/nature of aggressiveness in rave/dance clubs commonly frequented by E users;

- The role of $E$ in relationships between users who are members of two socially estranged communities residing in the same geographic region, Northern Ireland.

Table 1. Brief Descriptions of the Emergence of Psychotropic Drugs Year

\begin{tabular}{|c|c|c|c|c|}
\hline Drug $^{a}$ & Year Introduced ${ }^{b}$ & Country & Effects & Initial Uses \\
\hline LSD “Acid" & $1938-1945$ & Switzerland & Sensory hallucinations & $\begin{array}{l}\text { Treatment for } \\
\text { alcoholism, used in } \\
\text { psychotherapy }\end{array}$ \\
\hline $\mathrm{MDA}^{c}$ & 1910 & Germany & Euphoria, empathy & $\begin{array}{l}\text { Appetite suppressant, } \\
\text { psychotherapy }\end{array}$ \\
\hline $\begin{array}{l}\text { MDEA or MDE } \\
\text { "Eve" }\end{array}$ & Unknown & Unknown & $\begin{array}{l}\text { Similar to MDMA except } \\
\text { milder. Fewer stimulant } \\
\text { properties and may } \\
\text { produce more } \\
\text { introspection than MDMA }\end{array}$ & Unknown \\
\hline MDMA "Ecstasy" & $1912-1914$ & Germany & $\begin{array}{l}\text { Euphoria, empathy, mild } \\
\text { hallucinations at times }\end{array}$ & $\begin{array}{l}\text { Appetite suppressant, } \\
\text { although not marketed } \\
\text { as such; } \\
\text { psychotherapy }\end{array}$ \\
\hline Mescaline & $1895-1919$ & $\begin{array}{l}\text { Synthesized by } \\
\text { Ernst Splith, country } \\
\text { unknown }\end{array}$ & $\begin{array}{l}\text { Hallucinations although } \\
\text { less powerful than LSD }\end{array}$ & Respiratory stimulant \\
\hline $\begin{array}{l}\text { PCP "Angel } \\
\text { dust" }\end{array}$ & 1957 & $\begin{array}{l}\text { Synthesized by } \\
\text { Parke-Davis; British } \\
\text { patent (1960), US } \\
\text { patent (1963) }\end{array}$ & Disorientation, sedation & Surgical anesthetic \\
\hline
\end{tabular}

Sources: (1-5).

${ }^{a}$ LSD (D-lysergic acid diethykamide); MDA (methylenedioxyamphetamine); MDEA (methylenedioxiethylamphetamine);

MDMA (3,4,-methylenedioxymethamphetamine); PCP (phencyclidine).

${ }^{b} \mathrm{~A}$ range of years is given when sources have provided conflicting information.

"MDMA and MDEA represent two drugs within the "179-strong MDA family" (1).

\section{METHODS}

At the time of the study, drug research in Northern Ireland had focused primarily on self-report studies, all of which had been conducted in the 1990s. Several of these studies, plagued with major methodological problems, were not published for an academic audience yet locally some of the findings were reported as alarming news headlines. * However, one methodologically rigorous school-based study conducted by Miller and Plant (14) found lower prevalence rates of E among females in Northern Ireland (4.8\%) compared with their counterparts in England (7.0\%), Scotland

\footnotetext{
* Some of these local self-report studies were conducted and funded in part by agencies that served drug users. Study limitations included non-random samples, inappropriate procedures for calculating drug use prevalence, and problems associated with survey administration (for a more detailed account, see (13))
} 
$(10.6 \%)$, and in Wales (5.5\%), although the differences were not statistically significant. Prevalence rates for E use among males in Northern Ireland ranked second (10.7\%) to Scotland (14.0\%), but again, differences failed to reach statistical significance. These findings suggest that drug use prevalence among school youth in Northern Ireland in many ways is comparable to that of their peers in England, Scotland, and Wales. Studies of drug use among adults in the region also were limited although the 1994-1995 Northern Ireland Crime Survey (household-based) found a prevalence rate of $3 \%$ for $\mathrm{E}$. Lifetime prevalence rates, however, can include several "one-off" or "one-time" experimenters who are probably more similar to persons who abstain altogether than to persons who use with greater frequency (15). Additionally, survey data of drug use tell us little about the patterns of use and lifestyles of users yet qualitative studies of drug use in the north of Ireland including ethnographic accounts, were virtually nonexistent when the present study commenced. Longitudinal studies into drug use or related issues (e.g., HIV risk behaviors, also were lacking). These gaps made it difficult to gauge the nature of drug use in Northern Ireland. Moreover, the absence of drug studies also meant that relationships of trust between users and researchers had yet to be established.

The present study is based on 50 in-depth interviews with current or former $E$ users in Northern Ireland. It is part of a larger and on-going study that will include interviews with approximately 100 users. The criterion used for study inclusion was any use of $E$.

We used several methods to recruit respondents. First, we placed announcements or adverts of the study in cities, towns, and villages throughout Northern Ireland. We targeted venues that generally would be perceived as nonthreatening and would likely attract a large audience (e.g., record or music shops, health centers). Second, we advertised in a local club/music magazine that caters to a Northern Ireland population. The advert was published in three monthly issues during the study period. Third, we contacted several local organizations and notified them of our study. These agencies were diverse and included: youth outreach centers, universities, sexually transmitted disease (STD) clinics, gay men and women outreach programs, young offender programs, and drug user counseling or treatment centers. On several occasions we sent study announcements by post and then followed-up with phone calls to or visited with agency staff to discuss the study, in greater detail. Fourth, we asked interviewers to recruit some respondents through their own contacts and street sources. During these conversations, interviewers described the purpose of the study, emphasized the confidential nature of the study, and provided contact details for persons who might be interested in participating. Several contacts were made using this strategy. Fifth, we relied on snowball sampling, and asked respondents to refer friends and acquaintances. Sixth, in some instances we paid "recruiters" for each subsequent referral and completed interview. This method, however, was monitored closely and we had a set number of referrals (usually six) from each recruiter that we would accept. This method was particularly helpful in those outlying areas where we had few contacts. Clubs were not used as recruitment venues.

Interviews were conducted between October 1997 and August 1998. Four persons, two females and two males, served as interviewers (two of whom were the Project Directors). All of the interviewers were white, " Catholic ${ }^{1}$ and between the ages of 26 and 38 . Two interviewers were sociologists and two worked in the discipline of criminology. The Project Directors were full-time university lecturers and the two other interviewers were university graduate students. All of the interviewers were trained during a 2-week period before the study commenced and throughout the study period during staff meetings and discussions. Training topics included issues related to confidentiality and other ethical concerns, interviewing skills, and drug and club information. Interviews in Belfast generally were conducted in university offices that offered a great deal of privacy, or in other venues convenient to the respondent (e.g., private homes). Interviews with

\footnotetext{
${ }^{*}$ Additionally, all but one of the respondents were white (there are few ethnic minorities in Northern Ireland).

${ }^{1}$ It is not known whether the interviewers' religious backgrounds affected the validity of the responses. For two of the interviewers, the religious background could be determined on the basis of their first names. A third interviewer was a "foreigner" whose religion was unlikely to be ascertained by respondents
} 
respondents who lived outside of Belfast were conducted in private areas located within community agency sites or in private homes.

Respondents were assured of confidentiality at the beginning of and throughout the interview. Each of the interviewers signed a statement of confidentiality before the project commenced and this statement was framed and placed in full view in the room where most of the interviews occurred. Although we are uncertain as to whether the respondents truly believed that the study was confidential, the fact that refusals were rare and that several respondents referred friends and acquaintances for interviewing, suggests that most if not all respondents perceived that we were trustworthy.

Respondents were provided with a $£ 15$ music or book voucher for a completed interview. Interviews were conducted within a 1-2 $\mathrm{h}$ time period and focused on issues related to first, last, and usual use of $\mathrm{E}$, positive and negative drug experiences, drug use rituals and norms, health issues, and other items. Demographic and drug use history data were also collected. In some cases, project staff were affected personally by the interview data, particularly when respondents reported traumatic experiences (e.g., suicide of a friend, chronic depression). Regarding the effects on respondents, we never observed that respondents appeared to be adversely affected by the interview questions or through conversations with project staff. Alternatively, in several interviews, respondents appeared to enjoy the role of teaching nonusers about $\mathrm{E}$.

\section{RESULTS}

Slightly more than one-fifth of the sample $(22 \%)$ of the respondents were recruited through snowball sampling, $28 \%$ from one of six gatekeepers, $22 \%$ from hearing about the research through one of the study's employees, and $28 \%$ from reading an advert that contained information about the study * Our sample was not generated randomly hence we make no claims about generalizability. We report characteristics of the sample for descriptive purposes only (see Table 2). Males comprised $70 \%(N=35)$ of the sample and respondents' ages ranged from 17 to 45 years. Sixteen percent $(N$ $=8$ ) of the respondents identified their sexual preference as being gay or bisexual. Lifetime use of $E$ was defined in terms of the number of separate $E$ episodes or experiences rather than the number of tablets consumed over the lifetime. Although lifetime use of the drug varied considerably our sample was composed of a disproportionate number of "heavy" users, use $(8,9)$. For example, more than one-third of our sample (37\%) reporting using $E$ on at least 100 different occasions. In contrast, $25 \%$ had used the drug on 12 occasions or less. Most of the respondents (81\%) were current users of the drug whereas $19 \%$ of the sample were either former users $(N=8)$ or were not certain whether they would use again $(N=2)$.

Most respondents had used a number of different drugs. Lifetime prevalence was calculated for cannabis $(100 \%)$, amphetamine (92\%), LSD/magic mushrooms $(86 \%)$, cocaine $(44 \%)$, crack cocaine $(14 \%)$, and heroin $(10 \%)$. Daily or weekly use of these substances was rare during the 6month period before the interview with one exception: $40 \%$ of the respondents smoked cannabis daily during this 6 -month period. ${ }^{1}$ Most of the respondents (84\%) consumed pints of beer or lager on a weekly basis. The mean number of pints consumed per week was 14 (median=13).

\footnotetext{
${ }^{*}$ Of those respondents who had contacted the project staff and requested interviews, only a few potential respondents (e.g., six or fewer) failed to keep their appointment. We do not know of the number of $E$ users who were told about the study but never contacted us

"We acknowledge that the term "heavy user" is value-laden and we generally object to its use. We use the term here only to compare the number of lifetime E episodes among respondents in this study with that found in other studies

${ }^{1}$ Additionally, $66 \%$ of the sample smoked 20 or more cigarettes daily, during the 6 -month period before the interview
} 
Table 2. Selected Sample Characteristics $(N=50)$

\begin{tabular}{|c|c|c|c|c|c|c|c|}
\hline Respondent & Gender & Age & $\begin{array}{l}\text { Sexual } \\
\text { Preference }\end{array}$ & $\begin{array}{l}\text { Age at } \\
\text { Initiation }\end{array}$ & Lifetime Use & $\begin{array}{l}\text { Time Since } \\
\text { Last Use }\end{array}$ & $\begin{array}{l}\text { Former/ } \\
\text { Current User }\end{array}$ \\
\hline 001 & Male & 24 & Straight & 21 & $40-50$ & 10 months & Former \\
\hline 013 & Male & 26 & Straight & 22 & $80-100$ & 1 month & Current \\
\hline 015 & Male & 29 & Straight & 25 & Missing & 3 years & Former \\
\hline 017 & Male & 22 & Straight & 19 & $\begin{array}{l}\text { Uncertain; every } \\
\text { weekend last } 6 \text { months }\end{array}$ & 1 week & Current \\
\hline 022 & Female & 23 & Bisexual & 21 & $40-50$ & 4 days & Current \\
\hline 101 & Male & 30 & Straight & 26 & $\begin{array}{l}\text { Uncertain; used every } 3 \\
\text { days over a } 2 \text { year } \\
\text { period }\end{array}$ & 4 months & Current \\
\hline 102 & Female & 30 & Straight & 26 & 10 & 2 weeks & Current \\
\hline 103 & Male & 27 & Gay & 25 & 12 & 6 months & Current \\
\hline 106 & Female & 23 & Straight & 17 & Uncertain & 2 weeks & Current \\
\hline 107 & Male & 18 & Straight & 17 & $10-12$ & $11 / 2$ weeks & Current \\
\hline 108 & Male & 18 & Straight & 17 & $5-6$ & 2 weeks & Current \\
\hline 110 & Female & 33 & Gay & 26 & $50-60$ & 1 month & Current \\
\hline 113 & Male & 25 & Straight & 20 & $<12$ & 1 week & Current \\
\hline 115 & Male & 29 & Straight & 19 & $\begin{array}{l}\text { Uncertain; most } \\
\text { weekends over a 9-year } \\
\text { period }\end{array}$ & 2-3 days & Current \\
\hline 116 & Male & 33 & Straight & 27 & $50-100$ & 2 days & Current \\
\hline 117 & Male & 22 & Straight & 18 & $<10$ & 2 years & Former \\
\hline 118 & Female & 22 & Straight & 19 & 30 & 2 months & Current \\
\hline 120 & Female & 23 & Straight & 21 & 30 & 2 months & Current \\
\hline 121 & Male & 38 & Straight & 30 & 50 & 3 days & Current \\
\hline 122 & Male & 25 & Straight & 20 & Uncertain & 2 weeks & Current \\
\hline 123 & Male & 17 & Straight & 14 & 250 & 2 weeks & Current \\
\hline 124 & Female & 21 & Gay & 18 & 4 & $\begin{array}{l}3-4 \\
\text { months }\end{array}$ & Former \\
\hline 125 & Female & 24 & Gay & 20 & 10 & 2 months & Former \\
\hline 126 & Female & 21 & Straight & 19 & 20 & 2 months & Current \\
\hline 127 & Male & 23 & Straight & 19 & $>30$ & 1 month & Current \\
\hline 128 & Female & 23 & Straight & 20 & 50-100 & 3 months & Former \\
\hline 129 & Male & 23 & Straight & 20 & $200-250$ & 2 months & Former \\
\hline 201 & Male & 25 & - & 23 & 15 & 7 months & Current \\
\hline 203 & Female & 45 & Celibate & 33 & 900 & 1 day & Current \\
\hline 204 & Male & 27 & Straight & $18-19$ & 1000 & 4 days & Current \\
\hline 205 & Male & 30 & Straight & 25 & 150 & 2 days & Current \\
\hline 206 & Female & 24 & Straight & 19 & "Hundreds" & 2 days & Current \\
\hline 207 & Female & 32 & Straight & 28 & 10 & $\begin{array}{l}4-5 \\
\text { months }\end{array}$ & Current \\
\hline 208 & Male & 29 & Straight & 23 & $20-25$ & 2 months & Uncertain \\
\hline 209 & Female & 21 & Straight & $18-19$ & 20 & $7-8$ weeks & Current \\
\hline 210 & Male & 22 & Straight & 21 & "Hundreds" & 2 weeks & Current \\
\hline 211 & Male & 27 & Straight & 23 & $30-40$ & 6 weeks & Current \\
\hline 212 & Male & 19 & Straight & 14 & "Hundreds" & 2 days & Current \\
\hline 213 & Female & 34 & Gay & 32 & 7 & 1 week & Current \\
\hline 214 & Male & 17 & Straight & 14 & Missing & 3 weeks & Current \\
\hline 215 & Male & 20 & Straight & 14 & "Hundreds" & 2 days & Current \\
\hline 216 & Male & 18 & Straight & 14 & "Hundreds" & 4 days & Current \\
\hline 301 & Male & 29 & Gay & 24 & Uncertain & $2-3$ & Current \\
\hline 302 & Male & 34 & Straight & 32 & 2 & 1 year & Uncertain \\
\hline 303 & Male & 27 & Straight & 23 & 50 & 2 months & Uncertain \\
\hline 304 & Male & 18 & Straight & 16 & 30 & 3 weeks & Current \\
\hline 306 & Male & 28 & Gay & 22 & $>100$ & 1 week & Current \\
\hline 307 & Male & 24 & Straight & 19 & "Hundreds" & 2 weeks & Current \\
\hline 308 & Male & 24 & Straight & 20 & $>1000$ & 2 months & Current \\
\hline 309 & Male & 19 & Straight & $13-14$ & $>100$ & 2 weeks & Current \\
\hline
\end{tabular}


E has been defined as the "hug drug" (12, p. 1162) and its effects described as "passive sensuality" (16, p. 43). In one study (8, p. 59), respondents described the drug as "a feel good drug," "fun," "loving," "insightful," and "spiritual." Many of the respondents in our study used similar terms to describe the effects of E. For example, reference was made to being "loved up," "euphoric," and experiencing "rushes." These feelings appeared to make users more sociable rather than introverted, with respondents reporting being "emotionally close" to strangers, "hugging" strangers, "rubbing the backs" of strangers and acquaintances, "looking out for each other," and using other phrases that appeared to suggest a sense of fellowship or community among fellow drug users whom they did not know personally. As one user described it:

Everybody would be like friends, like you would be shaking hands and all with everybody. I am actually getting tingles remembering it. It's good; it's a great feeling. (respondent 304)

Others reported:

I've actually hugged strangers, (I would say to them), "Aw you're all right, can I give you a hug?" You'd sit and talk complete rubbish to them . . . (Respondent 113) ... and that complete stranger would also be on $E$ and if they were over they would pass you a remark or they're sitting there after sweating it out on the dance floor for a long time and you go over and sit beside them ... you don't know the person but you would've discussed absolutely everything with them . . . (respondent 124)

In Britain, some of this "rave-related behavior" has been described as "passe" (6, p. 26). In Northern Ireland, we too detected some weariness with such ostentatious displays of affection, and cynicism of what many perceived as the "falseness" or fakeness of the bon homme associated with being "loved up." Clearly E users themselves are capable of critically assessing some of the pervading images that are constructed around their drug usage. One user recounted: ". . I I think that a lot of that sort of 'emotionally close to strangers' thing is a bit of bullshit ..." (respondent 116) Others expressed similar concerns:

... it was shallow because you would have the same conversations with people over and over again and that showed that nobody was actually taking that amount of interest in what you were talking about. (respondent 013)

... we'd only really known each other from September and went "Hello," "What's the craic?" $\square$, you know, like that. But that night we sat talking for about five hours, bending each other's ear, you know? And the next day we were kind of "Aw, have to met up again," and "Had a great chat last night," but of course we both knew that we wouldn't . . . (respondent 128)

And some users became aware of the falseness of feeling emotionally close with strangers or acquaintances only after subsequent use of $E$ or greater exposure to the scene:

The first time you take it, you're quite innocent to it and you just love it, but I think the more I took it the more I was aware that this was just a front. Everyone was just, it was false affection from people, you know deep down that they don't give a shit about you; it was just the drugs making them amorous towards everything ... And so the more you become aware of it, you become a bit skeptical of it . . . (respondent 201) ... you're only close with them when you're on the Es. It's a false friendship. I used to like it but I don't now. Now I avoid strangers who get too friendly. (respondent 303) 
Other respondents reported that their tolerance of other "loved up" drug users was affected when they themselves were straight, or sometimes even during "come down":

\begin{abstract}
... both parties have to be on $E$. . . I remember we were out one night and we weren't on $E$ and this guy came up and he was on E, and it was his first $E$ and he was going "I love yous" and we were "Right OK, we know you love us, you told us that, so fuck off." (respondent 113)

... when you're straight, you've got no time for people, but when you're both off your heads, you love each other. And then when you're coming down, you think, "He's the biggest cunt ever." (respondent 308)
\end{abstract}

\title{
Aggressiveness in Dance/Rave Clubs
}

Anecdotal evidence suggests that alcohol probably creates more problems (e.g., violence) than drugs in club settings (17). Indeed, one persistent feature of the accounts of many $E$ users, linked to the pharmacologic effect of being "loved up," was the lack of aggression or violence on the dance/rave scene: "I've never in my life seen anybody fighting on Es" (respondent 108) And: "There is no doubt, definitely people do not fight on E" (respondent 205) Others responded similarly: $\square$ In this context, the question means "What's going on?" or "What's happening?"

... people who are on E who are subject to aggression? I don't think, . . . it doesn't compute as far as I am concerned, because, there's just, as far as they're concerned aggression's the last thing on their mind, you know. (respondent 015)

... the couple of times l've seen ( fights), it has been from people not on E. (respondent 122)

Often this claim was disparagingly juxtaposed to the disco or nightclub scene (associated by some users with the "era" of the researchers), the influence of alcohol and the view that such venues were plagued by the outbreak of fights. The responses below were typical of many respondents who viewed the $E$ experience as the antithesis of alcohol use and the potentially violent disco scene:

Maybe there is [violence] now because there are a lot of dickheads out there who would take $E$ and drink a load and get totally off their head and wouldn't know where they were at, but it's rare ... (respondent 206)

Sometimes, you know, outside you do see fights but they're usually people who're actually drinking. (respondent 127)

(There are no fights) unless the place is such, like half Es and half normal disco.

(respondent 210)

Thus, where respondents had witnessed fights or acts of violence, these events were normally explained as being linked to alcohol consumption and the "normal disco." In essence, these types of explanations provided justification for continued use of E-a drug that, by user definition, had a calming effect in an otherwise hostile environment. Other respondents, however, reported that fights did occur in clubs, but only when drug deals went wrong. A respondent, for example, reports that he never has observed a fight in a club that caters largely to E users, ". . . unless it has been drug dealing-related." (respondent 015) Another reports:

... it's normally between a couple of fellas and a dealer .. . [ perhaps] 'cause the dealer sold them a crap $E$ or not good enough buzz or something like that there. (respondent 214)

It is as if these respondents see these acts as being somehow separate from the $E$ scene altogether, despite the fact that every user has participated in a drug transaction and that drug transactions are a necessary component of the scene. A minority of respondents did however 
witness acts of aggression among users or link the use of $E$ to acts of violence: “. . . I've seen people turning nasty on E as well." (respondent 129)

I think, again, it was over a boyfriend-girlfriend type of thing. Some bloke went up and slapped another bloke and I know for a fact that both fellows concerned were on $E$ and I was taken aback by it because it was completely alien to me. I was like going, "Jesus, people aren't meant to fight in places where there's drugs," you know? (respondent 022)

One male respondent who had both witnessed and participated in what he referred to as "E fights," suggested:

I don't like to fight but if l'm provoked I fight . . . E mixed with drink makes you very aggressive if provoked. Gives you strength . . . E fights are nastier than drunken fights. Drunken fights make you stupid and clumsy. An E fight makes you fast and furious. The adrenaline rush -I think some guys get hooked on it. (repondent 303)

... people seem to have a great deal of tolerance for each other like, having said that like l've been in places like and l've seen people being aggressive. Not aggressive, like in somebody's face but like sort of adopting an aggressive manner like you know, it's mainly late teenage, early 20s, young men like. (respondent 116)

There were other indications that undermined the image of a nonviolent club scene. For example, some respondents frequented venues only after careful selection, for example, location, or the extent to which it was "trouble-free," that is, having little violence. (respondent 208) The desire to maintain the sense of "everyone having a good time"was itself suggested by one respondent as a possible reason for getting some users into potentially violent situations:

I've known people (on E) to be aggressive, kind of. Well, aggressive in that, not aggressive, but if a fight comes up, they'll feel that they have to take control of everything; they have to sort everything out ... it's such a good experience they think "I can't have this being bad for everybody else, right so l'll go over and sort that cunt out." (respondent 107)

We also noticed that even though some respondents believed strongly in a nonviolent atmosphere in club settings, they did not necessarily hold nonviolent views outside a club setting or when not using E. For example, a 19-year-old male respondent spoke of the "hostile" environment of pubs compared with raves. About one club site in particular (his favorite) he stated, ". . . there's no hostility at all in it, everybody's your friend-everybody-it's unbelievable." Later in the interview, however, he disclosed the following:

[I] hate people who put drugs down and put my music down; I get very hostile. [The respondent brought in a rave music tape to work and played it for two days.] [My coworkers] started slagging it off, I was going to fight them for it . . I I don't like people putting it down. (respondent 309)

\section{Relationships Between Catholics and Protestants}

Northern Ireland is a highly segregated community across a number of indices, with, for example, more than $90 \%$ of children attending either solely Protestant or solely Catholic schools (18), and many wards (particularly in working class areas) comprised of more than $90 \%$ of one religious denomination or the other (19). Although there are mixed middle class areas in some parts of greater Belfast, and evidence of considerable homogeneity of views between predominantly Catholic and Protestant small towns (20), recent demographic trends have suggested ever greater segregation between Protestant and Catholic working classes (19).

One topic of interest regarding $E$ and the rave/dance scene in Northern Ireland concerns the potential for Catholics and Protestants to meet in a recreational setting and begin to get to know 
each other. Nicholas Saunders (21) recounts how in 1994, just before the first IRA cease-fire, he interviewed persons, using a video camera in a Catholic club and ". . . lots of them were keen to tell me about the friendships they had made with members of the opposite sect who, they assured me, they would never have met otherwise."

We explored the views of our respondents with regard to this phenomenon. Their views appeared to fall within a number of categories. One respondent went so far as to argue that Ecstasy was brought into Northern Ireland to ". . . stop them all from shooting each other, get them all together." (respondent 215) Several others argued that use of E and the rave/dance scene had had a positive impact on intercommunity relations. As one working class Protestant argued:

\begin{abstract}
I think Ecstasy has had a very positive effect. I have to say living where I do which would be perceived as a Protestant loyalist area, I hadn't had much dealings with Catholics you know. I have to say I have made a couple of good friendships through it [Ecstasy] and it doesn't matter to me now whereas before I would have put my flag out on the twelfth and this sort of craic. ${ }^{1}$ Now I don't bother putting my flag out. (respondent 205) I'm a Catholic myself, I used to fight with the Protestants out in the park like but since we've took drugs like we don't give a fuck and people we used to scrap with, we go out and party with. (respondent 216)

[Ecstasy] greatly changed my socializing. Before, I wasn't much into religious mixing . . you would have known and talked to people but you wouldn't have gone out with somebody from the other religion and [Ecstasy] changed your perspective, you meet people you realize it's not all everybody's been saying, you know, talk to them. I know some guys I knew turned from being in bands ${ }^{2}$ and being staunch loyalists into mellow people who started having Catholic girlfriends and all. (respondent 117)

Ecstasy has bridged that gap socially. . . You would have had Catholics and Protestants but you would [also] have had loyalists and some republicans and to have them housed in one place was amazing like, you know? And they couldn't have done that unless they were off their faces, you know? (respondent 118)
\end{abstract}

But some respondents attributed the interactions to dealing rather than (or in addition to) $E$ use (i.e., one might have to mix with members of the other community if one wanted to score):

And sometimes through dealing as well you'd have to contact these people [ from the other community], you know [who] you would avoid normally ... (respondent 208)

Other respondents appear somewhat more cynical about the harmonizing potential of Ecstasy and the rave/dance scene. For example, some noted that $E$ may have improved interactions between Catholics and Protestants but only to a limited extent: "I wouldn't say they'd dance with each other like but they would talk to each other." (respondent 214) And when asked whether E brings Protestants and Catholics together, one respondent stated:

Of course it does when you're there in a club but the minute you're out the door the old tribal thing takes over again ... (respondent 203)

Another respondent agreed:

I say religion's not involved in the clubs but that starts and stops at the entrance to the club. Walking home you would be worried, walking past a bus that is coming from a Protestant area you would be worried if you were a Catholic and vice versa. (respondent 108)

\footnotetext{
* The flag referred to is the Union Jack which is flown in Loyalist areas during the period of orange marches that centers around July 12

${ }^{1}$ In this context, the statement, "this sort of craic," means "this sort of thing."

2 The bands to which the respondent refers are Loyalist marching bands
} 
Additionally, club location was mentioned as a relevant factor in several interviews. For example, it is clear from the interviews and observational data ${ }^{3}$ that the vast majority of clubs in the Belfast city center area are religiously mixed. However, in more rural areas, and indeed within religiously segregated areas of greater Belfast, there are rave/dance venues frequented almost exclusively by one religious denomination or the other. A respondent was interviewed from a rather large town/city outside Belfast in which Catholic residents account for a slight majority of the area's population. She was quite familiar with the club scene there, having frequented most of the venues. She reported that the clubs were quite segregated. In fact, she stated: "I don't honestly know any Protestants in (town/city name)." (respondent 022)

Several respondents used organized buses to transport them to club venues that were located an hour's drive or more away from their residences. Many of these venues were religiously mixed venues, however, such locations were not immune from sectarian tensions. Moreover, the transport itself at times was characterized as having sectarian tensions. As one working class Catholic respondent noted regarding his experiences on a bus to a well-known "mixed" rave/dance venue outside Belfast:

... there was a load came on from Tigers Bay [working class Protestant area] in their Rangers tops and UVF fucking tattoos and it just fucked me up the whole night . . it was just fuckin' [sings] "Hello, Hello, we are the Billy Boys" you know all that shit. Here's me "Ah for fuck's sake," and everybody else is going "Ah, keep your fucking trap shut"there was millions of them so nobody could say anything. (respondent 212)

Finally, a number of middle-class respondents clearly identified a class dynamic to the existence of both violence and sectarian tensions. In many such interviews the phrase "spide" appeared, which denoted young working class males, so called because of the stereotypical notion of the presence of "spider web" tattoos on the collar of the neck. Middle-class users noted that fights occurred only in those club venues with a heavy working class presence. And some users avoided clubs that were too "spidey" and disliked "after-hour" parties when too many "spides" showed up. As one middle class Protestant male suggested:

... I think the only way you get a religious divide is if, I mean the [club name] became very spide heavy. . . and a lot of my friends stopped going to it. . it's a stereotype, the spides do tend to fight quite a lot, they're more prone to aggression. It's hard to say without sounding really pompous and pretentious but say you have people from Twinbrook [i.e., a Catholic area] who know there's a gang from the Shankill [i.e., a Protestant area] down in the place, you're more likely to get fighting between them. (respondent 013)

\section{DISCUSSION}

This study explored E users' beliefs about social relationships as they relate to the drug scene.

Three areas were examined:

- The potential existence of "loved up" feelings popularly associated with the use of E;

- The presence or absence and or nature of aggressiveness in rave/dance clubs frequented by E users; and

- The role of $E$ in relationships between E-using members of two socially estranged communities.

In recent years, all three areas had been mentioned as being an integral part of the local $E$ folklore. Although several $E$ users in this study reported that the effects of the drug have been beneficial for social relations, other users feel that social relations are unaffected by the drug, thus a general

\footnotetext{
${ }^{3}$ Field researchers collected observational data in several clubs throughout Northern Ireland. These data are not reported here
} 
consensus regarding these issues is absent. We found, for example, that although several users report feeling empathetic towards strangers and acquaintances while under the influence of $E$, these feelings for the most part are short-lived, and disappear by or during the comedown stage. Empathy and kindness towards others therefore do not appear to be an integral part of a drug user lifestyle when users are not under the influence.

Similarly, claims of a nonviolent club scene were only partly substantiated by the interview data. Although several users stated that they had not witnessed acts of aggression in clubs, other respondents reported otherwise. Similarly, while we would concur that the combined effects of the $E$ and the mixed nature of some clubs may have had some positive impact in Catholic/Protestant relations, such features appear to be mitigated more by "setting," for example, club location and other characteristics of the venue. Additionally, the socio-economic background of users appears to affect respondents' perceptions about the nature of violence in clubs and about Protestant-Catholic relations, with middle-class users more likely to blame working class users for difficulties in these areas. Class segregation of the club scene has been noted elsewhere (22) and some of our data suggest that class interests (e.g., avoiding working class users) play a role in choosing club venues. Although more data are needed to examine this possibility further, such a finding would contradict the belief that Ecstasy promotes or encourages tolerance of those who are different.

Although some users do suggest changes in behavior that might have been perceived as sectarian (e.g., the flying of a flag) and friendships having been formed with members of the other community, such friendships would appear to have been based primarily around the social world associated with drug usage (e.g., arranging to meet up in a certain club). The extent to which $\mathrm{E}$ use and the related culture will make any structural impact on the divisions in Northern Irish society is extremely debatable.

In the context of drugs, various studies have examined "myth" regarding, for example, the views and expectations of drug users (23-25). Much of this literature is premised on the notion that drug users are exposed to a range of sources of information, much of it misleading. At times users may alter their behavior based on misinformation or use misinformation to justify continued use of drugs, both of which can have negative implications for personal health.

Ben-Yehuda, in his description of the historical mythmaking process in Israel, describes myth as implying a lie, or a manipulation, ". . . something that is not quite true, something whose relation to facts or to an objective reality is problematic at best" (26, p. 8). Sussman et al. (25, p. 2014) define what they term as drug use "myths," juxtaposing these "myths" to drug use facts, and then empirically test whether school children who have been removed from mainstream high school education in the United States subscribe to a series of 15 "myths." They admit that a dichotomy between facts and myths regarding drug use is not perfect, that some myth statements may not apply to early or occasional drug use, that there may be a "kernel of truth" in some myths.

Nonetheless borrowing from fact/myth research in tobacco and alcohol studies, they argue for such a split. Their distinction is that "Questionable beliefs that justify drug use, then, are labeled "myths," whereas reasonably accurate anti-drug-use beliefs are labeled "facts" " (25, p. 2015). For these scholars, the determining criterion for distinguishing between what constitutes fact and fiction, reality and myth, is therefore whether or not drug related information encourages or discourages drug usage.

In seeking to explore some of the views of E users, we deliberated for some time on those views that we considered as truthful or accurate and those that we considered were not. In some instances we found a bifurcation between "reality" and "myth" somewhat problematic concerning both the physical/pharmacologic effects and social/communal relationships. It is perhaps unsurprising that finding such clear distinction is difficult among the views of $E$ users given similar problems regarding both popular and academic accounts of the drug. For example, while the media image of drug usage generally tends to be sensationalist and inaccurate (27, p. 185-222), and 
reports regarding $E$ in particular have been criticized $(6$, p. 25$)$. ${ }^{*}$ Similarly with regard to studies that examine the effects of MDMA, findings tend to reflect the traditional variances associated with relatively new street drugs. Specifically, while the medical literature contains considerable case reports involving "heavy," recreational, or first-time E users and describes psychiatric, negative physical effects, or death after ingestion [see (28-33)], longitudinal and experimental studies of humans are limited, and a heated debate on effects remains (21). In sum, the vagaries of "myth/reality" distinctions among E users should be seen as analogous to, and part of, the broader contested discourses concerning the drug and its effects.

Perhaps what is more useful in understanding the significance of "myths" among drug users is to offer a more fluid notion of mythmaking. As suggested above, previous research into beliefs about drugs among drug users has been limited to some extent by a deterministic and objectivist tendency to conceptualize "questionable" beliefs or views as myth or fact depending on whether they support or discourage drug usage [e.g., see (25)]. In our view, however, such a view would offer a reductionist account of the role and function of myth in the use of $E$. If we view "myths" as (being and existing) somewhere along a spectrum between a) truth, b) sacred stories, and c) explainable, rational tales, symbolic of deeper political, social or cultural meaning (34, p. 30), then $E$ users' "myths" may be seen from a much broader perspective.

Although the relationship of such "myths" to objective reality may not be universal, or something that is not quite true (26, p. 8), myths may reflect some truth. A number of the users we interviewed clearly have experienced feelings of being "loved up," have perceived less aggression in clubs as well as improved Catholic/Protestant relations. While these feelings and perceptions may be contradicted by other users or internal inconsistencies, nonetheless they cannot be discounted simply because they may serve to legitimate drug consumption.

Additionally, myths may in fact serve useful and productive functions within a drug, using culture. For example, Parker (14) has suggested that the various myths among young drug users concerning the death of Leah Betts may be viewed as cautionary tales or functional narratives, used within the drug, using subculture to reinforce safe drug use messages (e.g., the need to consume appropriate amounts of water when dancing after consuming E). Similarly, although $E$ users may extol the nonviolent virtues of $E$ and link the likelihood of aggression to consumption of alcohol, dealing-related incidents, or the socio-geographical location of clubs, the net result may still be development of sensible conflict avoidance techniques.

In terms of Catholic/Protestant relations, E users' myths may reflect a number of deeper symbolic meanings. We have previously argued that discourses on the nature and extent of drug use in the North can only be understood in relation to the ideological, political, and practical context of the Northern Ireland conflict and peace process (36). A view of E as contributing to improved intercommunal relations in Northern Ireland, may reflect an amalgam of material differences in post1994 cease-fire local clubs and an aspiration among young drug users to leave behind 30 years of political and sectarian conflict. The desire to locate the causes and protagonists of the conflict in Northern Ireland in a notion "otherness," outside one's own religious, political, or social grouping is well documented $(37$, p. $32 ; 42)$. In such a context, the notion of $E$ and the rave scene as a haven from division and conflict (albeit one mitigated by the presence of working class users for some middle-class respondents) is understandable.

\footnotetext{
* Measham et al. argue that the British media have fixated either on the small number of deaths that can be directly related to $\mathrm{E}$, the mixing of unpleasant substances in the production process, or the environmental context in which $\mathrm{E}$ is taken.

* Leah Betts was a young female who died after taking $E$ and whose death raised considerable media interest in Britain. The cause of death, however, has been debated. Media reports have tended to attribute her death to the drug, itself whereas other reports have suggested that she died of dilutional hyponatremia ("build-up of water in the body") and that hormonal factors also may have played a role (35, p. 4).
} 
The emergence of a "moral panic" concerning E in post cease-fire Northern Ireland (38) may in turn have strengthened and encouraged a sense of solidarity amongst users. Demonized by the media and politicians, and under threat from paramilitaries in some instances, E users may have felt obliged to stress the positive social effects of the drug. Certainly a desire to tell their side of the story, dispel the propaganda and "cut through the hype" were themes, which ran throughout our interviews. Labeled as deviant $(39,40)$. Northern Ireland users may have responded in timehonored fashion (41) by creating and sustaining a series of "myths" with a complex array of functions other than simply justifying their own drug usage.

Finally, the data reported in this study suggested that users' beliefs about drugs and drug user lifestyles can change over time. Although we did not explore the factors that might account for those changes, some of the data appeared to suggest that perceptions about $E$ and $E$ culture can change as users gain more experience with the drug. Future research might focus on a more detailed analyses of factors associated with changing perceptions among users. This study examined $\mathrm{E}$ users' perceptions about social relations that characterize $E$ subcultures in a region of the world that has been divided by political conflict for several years. The extent to which these findings might apply to $E$ users in other countries is not known, particularly in areas that have not been affected by political conflict. Additional research might address this gap.

\section{ACKNOWLEDGMENT}

This study was funded by the Northern Ireland Statistics and Research Agency. Points of view are those of the authors.

\section{REFERENCES}

1. Tyler, A. Street Drugs; Hodder and Stoughton: London, 1995.

2. Eisner, B. Ecstasy: The MDMA Story; Ronin: Berkeley, CA, 1994.

3. Inciardi, J.A. The War on Drugs II; Mayfield: Mountain View, CA, 1992.

4. Shulgin, A.T. History of MDMA. In Ecstasy: The Clinical, Pharmacological and Neurotoxicological Effects of the Drug MDMA; Peroutka, Stephen J., Ed.; Kluwer Academic Publishers: Boston, 1990; $1-20$.

5. Stevens, J. Storming Heaven: LSD and the American Dream; Flamingo: London, 1987.

6. Measham, F.; Parker, H.; Aldridge, J. The Teenage Transition: From Adolescent Recreational Drug Use to the Young Aadult Dance Culture in Britain in the Mid-1990's. J. Drug Issues 1998, 28, 9-32.

7. Forsyth, A.J.M. Ecstasy and Illegal Drug Design: A New Concept in Drug Use. Int. J. Drug Policy 1995, 6, 193-209.

8. Beck, J.; Rosenbaum, M. Pursuit of Ecstasy: The MDMA Experience; SUNY: Albany, New York, 1994.

9. Solowij, N.; Hall,W.; Lee, N. Recreational MDMA Use in Sydney: A Profile of 'Ecstasy' Users and Their Experiences with the Drug. Br. J. Addic. 1992, 87, 1161-1172.

10. Spruit, I.P. Ecstasy in the Netherlands: A Summary of the Results of Six Projects; Ministry of Health, Welfare and Sport: Rijswijk, 1997.

11. Calafat, A.; Stocco, P.; Mendes, F.; Simon, J.; van de Wijngaart, G.; Sureda, M.P.; Palmer, A.; Maalst'e, N.; Zavatti, P. Characteristics and Social Representation of Ecstasy in Europe; IREFREA and European Commission: Palma de Mallorca, 1998.

12. Beck, J. The Public Health Implications of MDMA Use. In Ecstasy: The Clinical,

Pharmacological and Neurotoxicological Effects of the Drug MDMA; Peroutka, S.J., Ed.; Kluwer Academic Publishers: Boston, 1990; 77-103.

13. Higgins, K.; McElrath, K. The Trouble with Peace: The Cease-Fires and Their Impact on Drug Use Among Youth in Northern Ireland. Youth and Society, in press.

14. Miller, P.; Plant, M. Drinking, Smoking, and Illicit Drug Use Among 15- and 16-year-olds in the United Kingdom. Br. Med. J. 1996, 313, 394-397.

15. Parker, H. In Drug Pathways in the 1990's, Paper presented at the NISRA Conference on Illicit Drugs andYoung People, Mar 21, 1997,Kells, Northern Ireland, 1997.

16. Klee, $\mathrm{H}$. The Love of Speed: An Analysis of the Enduring Attraction of Amphetamine Sulphate for British Youth. J. Drug Issues 1998, 28, 33-56. 
17. Wise, J. Alcohol, Not Drugs, Causes Most Problems at Nightclubs. Br. Med. J. 1997, 315, 1179. 18. Gallagher, A.; Cormack, R.; Osborne, R. Religion, Equity and Education in Northern Ireland. Br. Educational Res. J. 1994, 20, 507-518.

19. Geddis, P., Ed. Focus on Northern Ireland: A Statistical Profile; HMSO: London, 1997.

20. O'Mahony, D.; McEvoy, K.; Geary, R.; Morison, J. Crime Community and Locale: The Northern Ireland Community Crime Survey; Ashgate: Aldershot, Ireland, 1999.

21. Saunders, N. Ecstasy and the Dance Culture; Wheatons: Exeter, 1995; Quotation from web site http://ecstasy.org.

22. Howes, S. Club Class. New Statesman and Society 1990, 16, 18-19.

23. Peroutka, S.J. Recreational Use of MDMA. In Ecstasy: The Clinical, Pharmacological and

Neurotoxicological Effects of the Drug MDMA; Peroutka, Stephen J., Ed.; Kluwer Academic

Publishers: Boston, 1990; 53-62.

24. Stacy, A.; Newcomb, M.; Bentler, P. Cognitive Motivation and Drug Use: A 9-Year Longitudinal Study. J. Abnorm. Psychol. 1991, 100, 502-515.

25. Sussman, S.; Dent, C.W.; Stacy, A.W. The Relations of Pro-Drug Myths with Self-Reported

Drug Use Among Youth at Continuation High Schools. J. Appl. Soc. Psychol. 1996, 26, 2014-2037. 26. Ben-Yehuda, N. The Masada Myth: Collective Memory and Mythmaking in Israel; University of Wisconsin Press: Madison, WI, 1995.

27. Goode, E.; Ben-Yehuda, N. Moral Panics: The Social Construction of Deviance; Blackwell: Oxford, 1994.

28. Brown, C.; Osterloh, J. Multiple Severe Complications from Recreational Ingestion of MDMA (“Ecstasy"). JAMA 1987, 258, 780-781.

29. Ellis, A.J.; Wendon, J.A.; Portmann, B.; Williams, R. Acute Liver Damage and Ecstasy Ingestion. Gut 1996, 38, 454-458.

30. Maxwell, D.L.; Polkey, M.I.; Henary, J.A. Hyponatraemia and Catatonic Stupor After Taking "Ecstasy." Br. Med. J. 1993, 307, 1399.

31. McGuire, P.; Fahy, T. Chronic Paranoid Psychosis After Misuse of MDMA ("Ecstasy"). Br. Med. J. 1991, 302, 697.

32. O'Connor, B. Hazards Associated with the Recreational Drug "Ecstasy." Br.J. Hosp. Med. 1994, 52, 507-514.

33. Williams, H.; Meagher, D.; Galligan, P. M.D.M.A. (“Ecstasy”); A Case of Possible Drug-Induced Psychosis. Ir. J. Med. Sci. 1993, 162, 43-44.

34. Fitzpatrick, P. The Mythology of Modern Law; Routledge: London, 1992.

35. Druglink. The Effects of E on Harm Reduction. 1996 (January/February).

36. McEvoy, K.; McElrath, K.; Higgins, K. Does Ulster Still Say No? Drugs, Politics and Propaganda in Northern Ireland. J. Drug Issues 1998, 21, 127-155.

37. McGarry, J.; O'Leary, B. Explaining Northern Ireland: Broken Images; Blackwell: Oxford, 1995.

38. Hollywood, B. Dancing in the Dark: Ecstasy, the Dance Culture and the Moral Panicking of

Contemporary Northern Ireland. Crit. Criminol. 1997, 8, 62-78.

39. Becker, H. Outsiders: Studies in the Sociology of Deviance; Macmillan: London, 1963.

40. Lemert, E. Human Deviance, Social Problems and Social Control; Prentice Hall: Englewood Cliffs, NJ, 1967.

41. Young, J. The Drug Takers: The Social Meaning of Drug Use; MacGibbon \& Kee/Paladin: London, 1971.

42. Ruane, J.; Todd, J. The Dynamics of Conflict in Northern Ireland: Power, Conflict and Emancipation; Cambridge University Press: Cambridge, 1996.

\section{THE AUTHORS}

Karen McElrath is a Reader in Sociology at Queen's University, Belfast. She recently completed the first qualitative study of heroin use in Northern Ireland. From that research, she currently is investigating risk behaviors among injecting drug users in the context of political conflict, as well as selfhelp strategies used by injectors in the absence of formal treatment.

Kieran McEvoy is a Reader in the Institute of Criminology and Criminal Justice, Queen's University, Belfast. $\mathrm{He}$ and Karen McElrath are currently exploring Ecstasy users' perceptions of negative drug experiences, as well their perceptions about long-term health consequences of drug-taking. Other current research interests include paramilitary prisoners, restorative justice, and conflict resolution. 